2. Glover ML, Cole E, Wolfsdorf J. Vancomycin dosage requirements among pediatric intensive care unit patients with normal renal function. J Crit Care 2000;15:1-4.

3. Maloni TM, Belucci TR, Malagutti SR, Furtado GHC. Describing vancomycin serum levels in pediatric intensive care unit (ICU) patients: are expected goals being met. BMC Pediatr 2019;19:240.

4. Arias Lopez MP, Fernandez AL, et al. Pediatric index of mortality 2 as a predictor of death risk in children admitted to pediatric intensive care units in Latin America: A prospective, multicenter study. J Crit Care 2015;30:1324-1330.

No conflict of interest.

\section{CPS-038 STABILITY TO HIGH TEMPERATURES OF THE ANTIMICROBIALS USED IN OUTPATIENT PARENTERAL ANTIMICROBIAL THERAPY PROGRAMMES}

${ }^{1} \mathrm{M}$ Mejias Trueba*, 'L Herrera Hidalgo, 'JL Pérez Blanco, 'MV Gil Navarro, ${ }^{2} \mathrm{LE}$ López Cortés, ${ }^{3} \mathrm{JM}$ Carmona Caballero, ${ }^{4} \mathrm{R}$ Luque Márquez. ${ }^{1}$ Hospital Universitario Virgen Del Rocio, Hospital Pharmacy, Sevilla, Spain; ${ }^{2}$ Instituto De Biomedicina De Sevilla Ibis, Clinical Unit of Infectious Diseases-Microbiology and Preventive Medicine, Sevilla, Spain; ${ }^{3}$ Hospital Universitario Virgen Del Rocío, Pharmacy, Sevilla, Spain; ${ }^{4}$ Hospital Universitario Virgen Del Rocio, Clinical Unit of Infectious Diseases-Microbiology and Preventive Medicine, Sevilla, Spain

10.1136/ejhpharm-2020-eahpconf.139

Background and importance Outpatient parenteral antimicrobial therapy (OPAT) programmes allow the administration of intravenous antimicrobials to non-hospitalised patients, offering numerous advantages. During administration, antimicrobial solutions could experience an increase in temperature after exposure to room temperature. However, studies on stability at high temperatures $\left(35-37^{\circ} \mathrm{C}\right)$ are still very scarce.

Aim and objectives To collect high temperature stability data $\left(35-37^{\circ} \mathrm{C}\right)$ for antimicrobials used in an OPAT programme.

Material and methods Antimicrobials used in the OPAT programme of two third level hospitals were compiled. Different sources of information were consulted (data sheet, Stabilis and Micromedex) to find stability studies for each antimicrobial at high temperatures $\left(35-37^{\circ} \mathrm{C}\right)$. Data were classified in three groups: antimicrobials with stability data at concentrations used in OPAT, antimicrobials with stability data at other concentrations and antimicrobials without stability data.

Results The stability of 24 antimicrobials was studied: in $16.66 \%$ of cases, stability studies were found at the temperatures mentioned for the concentrations used; in 50\% of cases there were stability data, but for concentrations other than those used in clinical practice and in the remaining $33.33 \%$, there were no published data for the aforementioned temperatures.

- Stability data found:

a. At the concentrations used: acyclovir $3-5 \mathrm{mg} / \mathrm{mL}(2$ weeks), cefazolin $12.5-25 \mathrm{mg} / \mathrm{mL}$ (12 hours), gentamicin $2.5 \mathrm{mg} / \mathrm{mL}$ (96 hours) and voriconazole $2 \mathrm{mg} / \mathrm{mL}(4$ hours).

b. Other than the concentrations used: aztreonam 60 or $100 \mathrm{mg} / \mathrm{mL}$ (24 hours), ampicillin $0.0125 \mathrm{mg} / \mathrm{mL}(24$ hours), cefepime $0.5 \mathrm{mg} / \mathrm{mL}$ (4 hours) and $50 \mathrm{mg} / \mathrm{mL}$ (13 hours), ceftazidime $0.1 \mathrm{mg} / \mathrm{mL}$ ( 2 hours) and 120 $\mathrm{mg} / \mathrm{mL}$ (8 hours), ceftriaxone $10 \mathrm{mg} / \mathrm{mL}$ (2 weeks), clindamycin $0.25 \mathrm{mg} / \mathrm{mL}$ (24 hours), daptomycin 100 $\mathrm{mg} / \mathrm{mL}$ (6 hours), meropenem $5 \mathrm{mg} / \mathrm{mL}$ (4 hours), piperacillin-tazobactam 128/16 mg/mL (24 hours), penicillin G $0.13 \mathrm{MUI} / \mathrm{mL}$ (5 hours), tobramycin $20 \mathrm{mg}$ / $\mathrm{mL}$ (3 weeks) and vancomycin $1 \mathrm{mg} / \mathrm{mL}$ (4 days). c. Antimicrobials without studies at high temperatures: amphotericin B, cloxacillin, ertapenem, foscarnet, fluconazole, ganciclovir, sulbactam and teicoplanin.

Conclusion and relevance

- Stability data at high temperatures were scarce for the antimicrobials used in the OPAT programme. It would be convenient to carry out corresponding studies.

- In warm environments, where the OPAT programme is established, antimicrobials and their concentrations should be adapted to the available information.

\section{REFERENCES AND/OR ACKNOWLEDGEMENTS}

No conflict of interest.

\section{CPS-039 NOSOCOMIAL INFECTION BY MULTIRESISTANT PATHOGENS IN KIDNEY TRANSPLANT PATIENTS}

MJ Morales Lara*, R Tamayo Bermejo, A Luna Higuera. Hospital Regional Universitario Carlos Haya, Pharmacy, Malaga, Spain

10.1136/ejhpharm-2020-eahpconf.140

Background and importance Immunosuppression related to organ transplant is a risk factor for multidrug resistant infections.

Aim and objectives To evaluate the prevalence of nosocomial infections (NI) by multidrug resistant (MDR) pathogens, aetiologic agents and treatments given to a cohort of patients undergoing kidney transplantation (KT).

Material and methods A retrospective observational study was carried out in a cohort of patients having undergone a KT during 2016-2017. Variables collected: demographics, clinical (type of KT and aetiologic agent) and therapeutic (induction immunosuppressant treatments and empirical and targeted antimicrobials) data.

Results Sixty-four patients who had undergone a KT $(84.4 \%$ from a cadaver, $7.8 \%$ from a live donor and 7.8\% kidneypancreas) were included (mean age 53.6 15.3 years, $72.9 \%$ men).

The most frequent induction immunosuppressant treatments were: basiliximab + mycophenolate-mofetil + steroid + tacrolimus $(31.2 \%)$ and thymoglobulin + mycophenolate-mofetil+steroid + tacrolimus $(65.6 \%)$.

Eight of 64 patients developed NI by MDR pathogens during hospitalisation as a result of the KT (prevalence 12.5\%), isolating a total of 10 multiresistant causative agents: Escherichia coli (30\%), Pseudomonas aeruginosa and Klebsiella pneumoniae (extended spectrum beta lactamase producing, oxa-48 carbapenemase producing (20\% each) and carbapenemase producing (10\%)).

The sources of NI were: urinary tract (50\%), central venous catheter (30\%) and abdominal (20\%).

Based on patient symptoms, empirical administered antibiotics were: ceftazidime (30\%), ciprofloxacin (20\%), ceftriaxone (20\%), meropenem, levofloxacin (10\%) and piperacillin-tazobactam (10\%). In all cases, once the aetiologic agent was isolated, targeted treatment was used.

It is worth noting the use of ceftazidime-avibactam in two cases of infection with MDR carbapenemase oxa-48 producing $K$ pneumoniae. None of the patients died due to the NI. Of the patients treated with the immunosuppressant regimen that included basiliximab, 40\% developed NI by MDR pathogens in contrast with the group that received the regimen including 